\title{
Development and validation of a stability indicating related substances of Opicapone by reverse phase high performance liquid chromatography and its degradation
}

\author{
Ramachandran Dittakavi*, Neeharika Tirumalasetty \\ Department of Chemistry, Acharya Nagarjuna University, Nagarjuna Nagar, Guntur, Andhra Pradesh-522 510, India.
}

\begin{tabular}{|c|c|}
\hline ARTICLE INFO & ABSTRACT \\
\hline Received on: 04/09/2021 & ector of 2998 instrument was used to \\
\hline Accepted on: 15/11/2021 & separate Opicapone's associated contaminants utilizing a verified stability-indicating Reverse phase high performance \\
\hline Available Online: 05/02/2022 & $\begin{array}{l}\text { liquid chromatography (RP-HPLC) procedure. The chromatographic separation of Opicapone with its associated } \\
\text { impurities is obtained by utilizing gradient elution with a tampon containing } 0.1 \% \text { triethyl amine and acetonitrile }\end{array}$ \\
\hline $\begin{array}{l}\text { Key words: } \\
\text { Opicapone, related impurities, } \\
\text { HPLC, development, } \\
\text { validation. }\end{array}$ & $\begin{array}{l}\text { as a mobile phase with a flow rate of } 1 \mathrm{ml} / \text { minute at ambient temperature, on the Agilent eclipse C } 18 \text { column }(150 \\
\times 4.6 \mathrm{~mm}, 3.5 \mu \text { ). The PDA detector's instrumental settings included a wavelength of } 225 \mathrm{~nm} \text {. The separation of } \\
\text { Opicapone and its impurities required a } 20 \text {-minute run time. The new approach was tested according to the guidelines } \\
\text { of the International Conference on Harmonization. Limit of quantification (LOQ) and Limit of detection (LOD) were } \\
\text { determined with regard to test concentration for the Opicapone and its contaminants. Parameters like specificity, } \\
\text { linearity, accuracy, ruggedness, and robustness were examined as a part of the technique validation process, and the } \\
\text { results were determined to be within permissible limits. Hence, this method is a greener and used for the detection of } \\
\text { impurities (i.e, Opicapone and its related impurities). }\end{array}$ \\
\hline
\end{tabular}

\section{INTRODUCTION}

For patients with Parkinson's disease, the medicine Opicapone, available under the brand name Ongentys, is commonly used combined with levodopa (Lopez et al., 2008; Scholz et al., 2011) in people with Parkinson's disease (Barranco et al., 2009; Macleod et al., 2014). A few typical side effects include dyskinesia (Fabbrini et al., 2007; Thanvi and Robinson, 2007), constipation (Bharucha, 2007), elevated blood creatine kinase (Brewster, 2020; Moghadam et al., 2016), hypotension (Chisholm and Anpalahan, 2017; Low, 2015), and weight loss. Opicapone, which has been shown to restore dopamine (Hussain and Lokhandwala, 2003) levels in areas of the brain that control movement and coordination, does so through the inhibition of

\section{"Corresponding Author}

D. Ramchandran, Department of Chemistry, Acharya Nagarjuna University, Guntur, India.E-mail: ramchandran.anitha19@gmail.com
catechol-O-methyltransferase (COMT) (Bonifácio et al., 2007; Glatt et al., 2003). Levodopa can be given orally, and it has a more effective action when combined with Neurotransmitter dopamine (PEG-PEA). The enzyme COMT is involved in the breakdown of levodopa in the body, and Opicapone prevents it. Levodopa remains active for longer because of this. These measures improve Parkinson's disease symptoms, such as stiffness and sluggishness. In patients with malignancies that emit catecholamines (Eisenhofer et al., 2004) (such as epinephrine), such as phaeochromocytoma (Hamidi et al., 2017; Tevosian and Ghayee, 2019) or paraganglioma, it is contraindicated since it hinders catecholamine breakdown as a COMT inhibitor. In addition, patients who have experienced neuroleptic malignant syndrome (NMS) (Ananth et al., 2004; Strawn et al., 2007) or non-traumatic rhabdomyolysis (Warren et al., 2002) should not use sertindole since it may create pharmacological interactions with monoamine oxidase inhibitors, which are not utilized as antiparkinsonians. The COMT inhibitors tolcapone and entacapone rarely caused NMS and concomitant rhabdomyolysis. This phenomenon generally occurs after COMT 
<smiles>COc1c(O)c([N+](=O)[O-])cc(C(=O)O)c1[N+](=O)[O-]</smiles>

Opicapone Imp-1<smiles>COc1nc(C)c(Cl)c(C)c1/C(N)=N/O</smiles><smiles>COc1cc(C(=O)O)cc(C(C)=O)c1O</smiles>

Opicapone Imp-2<smiles>Cc1[nH]c(=O)c(/C(N)=N/O)c(C)c1Cl</smiles>

Opicapone $\operatorname{Im} p-5$<smiles>COc1nc(C)c(Cl)c(C)c1C#N</smiles><smiles>Cc1c(Cl)c(C)[n+]([O-])c(Cl)c1-c1noc(-c2cc(O)c(O)c([N+](=O)[O-])c2)n1</smiles>

Opicapone

Figure 1. Chemical representations of Opicapone and its impurities.

inhibitor treatment, such as when the levodopa dose is lowered or the COMT inhibitor treatment is discontinued. People who are also using non-selective monoamine oxidase inhibitors (Gillman, 2018; Stahl and Felker, 2014), or who have pheochromocytoma, paraganglioma, or other catecholamine secreting neoplasms, should avoid using Opicapone.

The research published here use High performance liquid chromatography (HPLC) to measure Opicapone and its associated contaminants. Till now, there have few HPLC reports available. But, we employed HPLC to isolate Opicapone from its contaminants. Figure 1 shows the chemical structures of Opicapone and its impurities.

\section{EXPERIMENTAL STUDY}

\section{Chemicals and reagents}

HPLC grade of triethylamine, water, and acetonitrile, all of which were acquired from Merck India Ltd in Mumbai, India, were used. The reference standards for Opicapone and its related impurities were provided by Candila health care ltd, Ahmedabad, India. A capsule dosage form of Ongentys (50 mg) was acquired from Zydus, Cadila healthcare Ltd, Ahmedabad-382210, Gujarat, India.

\section{Instrumentation}

Waters alliance liquid chromatography (model e-2695) was utilized in this investigation, with the aid of the model 2998 photo diode array detector and the Empower 2.0 data management system.

\section{Mobile phase-A}

\section{Acetonitrile}

\section{Preparation of mobile phase-B}

$1 \mathrm{ml}$ of triethylamine is dissolved in 11 of HPLC grade water and filter through $0.45 \mu$ filter paper.

\section{Optimization of mobile phase}

Different trails have conducted their experiments, with different buffers and different mobile phases being utilized in the development of the approach. No peaks have been appropriately divided in all paths. As a result of this approach, all the peaks are resolved, and the limits are fulfilled on all suitability factors.

\section{Chromatographic conditions}

The HPLC analysis was conducted on a reverse-phase HPLC system, which employed gradient elution (Table 1) with acetonitrile and $0.1 \%$ triethylamine as the mobile phase and an Agilent Eclipse $\mathrm{C} 18(150 \times 4.6 \mathrm{~mm}, 3.5 \mu \mathrm{m})$ column. The retention time of Opicapone was observed at 13.2 minutes with a run time of 20 minutes. A wavelength of $225 \mathrm{~nm}$ was observed by using PDA detector.

From all the above results, it is clear that the Opicapone was separated from its five impurities with simple gradient method and having good resolution between each impurity.

The comparision between the previously published works with the current method were given in the form of a Table 2.

\section{Green chemistry and AGREE tool}

Green analytical chemistry aims to make analytical techniques less harmful to the environment and more humanfriendly. The amount and toxicity of reagents used, generated

Table 1. Gradient program.

\begin{tabular}{ccc}
\hline Time (minute) & Mobile phase-A & Mobile phase-B \\
\hline 0 & 80 & 20 \\
5 & 50 & 50 \\
10 & 40 & 60 \\
15 & 30 & 70 \\
17 & 80 & 20 \\
20 & 80 & 20 \\
\hline
\end{tabular}


Table 2. Comparison between new HPLC method in this paper and old methods.

\begin{tabular}{|c|c|c|c|c|c|c|c|}
\hline \multirow{2}{*}{$\begin{array}{l}\text { Parameter } \\
\text { Drug name }\end{array}$} & \multicolumn{2}{|c|}{ New HPLC method } & $\begin{array}{l}\text { Old HPLC method developed by } \\
\text { Daniela (2013) }\end{array}$ & \multicolumn{2}{|c|}{$\begin{array}{c}\text { Old HPLC method } \\
\text { developed by Daniela } \\
(2013) \\
\end{array}$} & \multicolumn{2}{|c|}{$\begin{array}{l}\text { (Daniela Goncalves et al., } \\
\text { 2011) }\end{array}$} \\
\hline & Opicapone & Imp-1-5 & $\begin{array}{c}\text { Active metabolite of } \\
\text { Opicapone (BIA) 9-1079 }\end{array}$ & Opicapone & BIA 9-1079 & Opicapone & Toicapone \\
\hline Range $(\mu \mathrm{g} / \mathrm{ml})$ & $5-75$ & $0.5-7.5$ & $0.04-4.0$ & $0.025-3$ & $0.025-3$ & \multicolumn{2}{|c|}{$10 \%-15 \%$} \\
\hline Retention time (minute) & 13.28 & $\begin{array}{l}4.7,6.8,9.5 \\
10.7,12.2\end{array}$ & 9.12 & 4.5 & 8.4 & - & - \\
\hline Mobile phase & \multicolumn{2}{|c|}{$\begin{array}{l}\text { Acetonitrile }+0.1 \% \\
\text { triethylamine }\end{array}$} & $\begin{array}{l}0.05 \mathrm{M} \text { monophosphate solution ( } \mathrm{pH}- \\
\text { 2.45): acetonitrile }\end{array}$ & \multicolumn{2}{|c|}{$\begin{array}{c}0.05 \mathrm{M} \text { monophosphate } \\
\text { solution }(\mathrm{pH}-2.45): \\
\text { acetonitrile }\end{array}$} & \multicolumn{2}{|c|}{$\begin{array}{l}\text { Acetonitrile and water with } \\
0.5 \% \text { acetic acid }(25: 75 \mathrm{v} / \mathrm{v})\end{array}$} \\
\hline Stationary phase & \multicolumn{2}{|c|}{$\begin{array}{c}\text { Agilent eclipse C18 }(150 \times \\
4.6 \mathrm{~mm}, 3.5 \mu\end{array}$} & Star C18 $(55 \times 4 \mathrm{~mm}, 3 \mu)$ & \multicolumn{2}{|c|}{ Star C18 $(55 \times 4 \mathrm{~mm}, 3 \mu)$} & \multicolumn{2}{|c|}{ C18 bonded to silica } \\
\hline Detection wavelength & \multicolumn{2}{|c|}{$225 \mathrm{~nm}$} & $257 \mathrm{~nm}$ & \multicolumn{2}{|c|}{$257 \mathrm{~nm}$} & \multicolumn{2}{|c|}{$270 \mathrm{~nm}$} \\
\hline $\begin{array}{l}\text { Greenness pictograms } \\
\text { via AGREE tool }\end{array}$ & & & & & & & \\
\hline
\end{tabular}

waste, energy requirements, the number of procedural steps, miniaturization, and automation are just a few of the many parameters taken into account when determining the greenness of an analytical approach. The application of greenness assessment criteria necessitates the use of specialized software such as The Appraisal of Guidelines for REsearch \& Evaluation (AGREE). As a result, for a thorough, adaptable, and clear assessment technique, we employed the Analytical GREEnness calculator, which offered a simply interpretable and useful result.

Diluent

Mobile phase was used as a diluent.

\section{Validation procedure}

International Conference on Harmonization (ICH) Q2 (R1) guidelines were used to verify the performance of several analytical parameters, including system appropriateness, precision, specificity, accuracy, linearity, robustness, LOD, LOQ, forced deterioration, and stability.

Standard stock solution. Load $50 \mathrm{mg}$ of Opicapone into a $100 \mathrm{ml}$ volumetric flask and mix in $70 \mathrm{ml}$ of sonicated diluent for 10 minutes to dissolve the contents. Then bring the total volume to the mark with more diluent.

Sample stock solution. Use $100 \mathrm{ml}$ volumetric flasks with diluent to transfer $129 \mathrm{mg}$ (50 mg of Opicapone) of sample. Make sure you filter the solution with a $0.45 \mu$ nylon syringe filter.

Impurity standard stock solution. Set up a $100 \mathrm{ml}$ volumetric flask, weighing $5 \mathrm{mg}$ of each imp-1, imp-2, imp-3, imp-4, and imp-5 inside of it. Pour in $70 \mathrm{ml}$ of solvent, then sonicate to dissolve it.

Spiked standard solution. Place $5 \mathrm{ml}$ of standard stock solution into a $50-\mathrm{ml}$ volumetric flask, then add $40 \mathrm{ml}$ of diluent. After that, add $5 \mathrm{ml}$ of impurity standard stock solution, and mix until full. Filter the sample through a $0.45 \mu$ syringe filter.
Spiked sample solution. Transfer $5 \mathrm{ml}$ of sample stock into a $50 \mathrm{ml}$ volumetric flask, add $40 \mathrm{ml}$ of diluent, and also add $5 \mathrm{ml}$ of impurity standard stock solution and makeup to the mark with diluent. Filter through $0.45 \mu$ syringe filter.

\section{Results and Discussion}

One of the biggest analytical difficulties in the creation of a new technique was separating active pharmaceutical components. The chromatographic conditions were altered to provide an optimal performance.

\section{Method validation}

ICH guidelines on system appropriateness, linearity, accuracy, precision, robustness, and stability were achieved by the improved RP-HPLC technique.

\section{System suitability}

To evaluate the applicability of devices, $50 \mu \mathrm{g} / \mathrm{ml}$ of Opicapone, $5 \mu \mathrm{g} / \mathrm{ml}$ each of imp-1, imp-2, imp-3, imp-4, and imp5 were injected into six replicates of spiked standard solution. The findings reveal that the fitness parameter of the machine conforms to the limit defined by ICH. Table 3 and Figure 2 present the system precision results and standard chromatogram, respectively.

Table 3. Results of system suitability.

\begin{tabular}{ccc}
\hline $\begin{array}{c}\text { System suitability } \\
\text { parameter }\end{array}$ & Acceptance criteria & $\begin{array}{c}\text { Drug name } \\
\text { Opicapone }\end{array}$ \\
\hline USP plate count & Not less than (NLT) 2000 & 16,428 \\
USP tailing & Not more than (NMT) 2.0 & 1.09 \\
USP resolution & NLT 2.0 & 2.75 \\
$\%$ RSD & NMT 2.0 & 0.51 \\
Retention time & NLT 2.0 & 13.284 \\
\hline
\end{tabular}




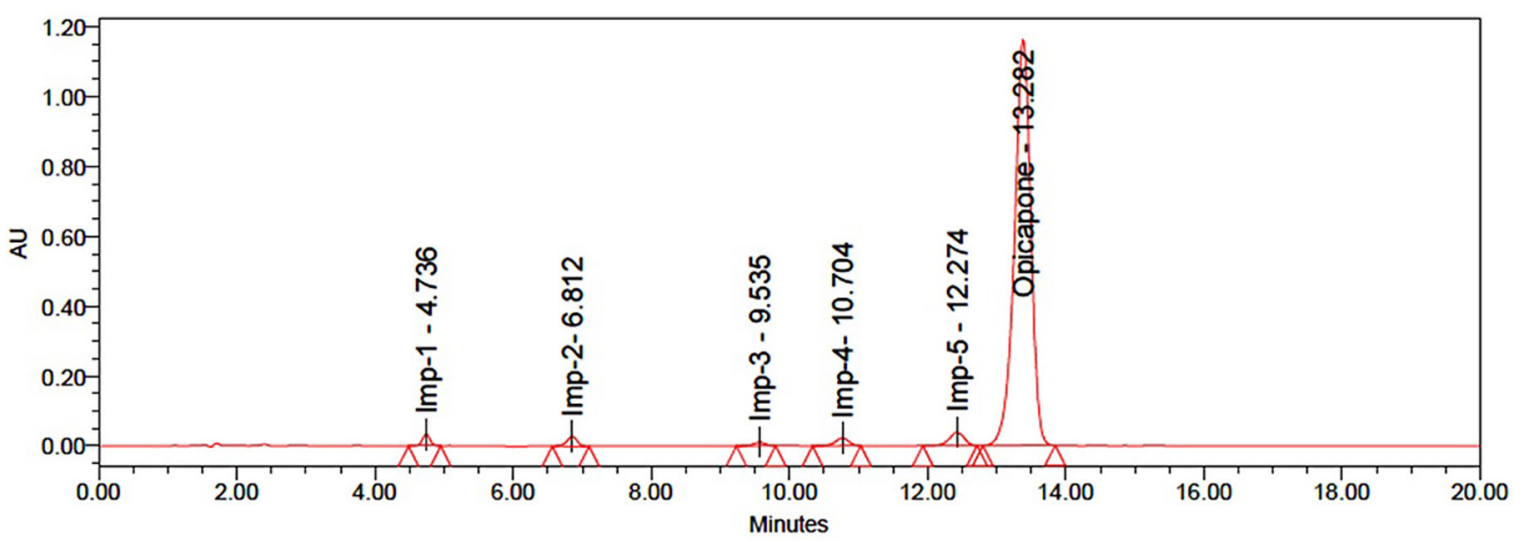

Figure 2. Standard chromatogram.

\section{Specificity}

To test the interference, placebo solutions, samples, and standards were tested independently in this test procedure. In the diagram below, you can see that the active ingredient, its associated compounds, and excipients were clearly separated from the blank and that the placebo did not interfere with the major peak.
Therefore, the process is specialized. Blank chromatogram was shown in Figure 3.

\section{Linearity}

To measure linearity, a calibration curve was created in which the peak area of each concentration was plotted against

Table 4. Linearity results of Opicapone and its impurities.

A

\begin{tabular}{|c|c|c|c|c|c|c|}
\hline \multirow[b]{2}{*}{ Linearity } & \multicolumn{2}{|c|}{ Imp-1 } & \multicolumn{2}{|c|}{ Imp-2 } & \multicolumn{2}{|c|}{ Imp-3 } \\
\hline & Conc. $(\mu \mathrm{g} / \mathrm{ml})$ & Area & $\begin{array}{c}\text { Conc. }(\mu \mathrm{g} / \\
\mathrm{ml})\end{array}$ & Area & $\begin{array}{c}\text { Conc. }(\mu \mathrm{g} / \\
\mathrm{ml})\end{array}$ & Area \\
\hline Linearity-1 & 0.50 & 25,994 & 0.50 & 26,336 & 0.50 & 11,641 \\
\hline Linearity-2 & 1.25 & 70,008 & 1.25 & 69,804 & 1.25 & 33,524 \\
\hline Linearity-3 & 2.50 & 122,200 & 2.50 & 132,539 & 2.50 & 61,008 \\
\hline Linearity-4 & 3.75 & 197,825 & 3.75 & 215,752 & 3.75 & 92,023 \\
\hline Linearity-5 & 5.00 & 263,228 & 5.00 & 280,819 & 5.00 & 119,688 \\
\hline Linearity-6 & 6.25 & 315,593 & 6.25 & 339,824 & 6.25 & 145,493 \\
\hline Linearity-7 & 7.50 & 379,273 & 7.50 & 408,256 & 7.50 & 177,216 \\
\hline Slope & \multicolumn{2}{|c|}{$50,691.95$} & \multicolumn{2}{|c|}{$54,806.35$} & \multicolumn{2}{|c|}{$23,404.21$} \\
\hline Intercept & \multicolumn{2}{|c|}{$2,263.91$} & \multicolumn{2}{|c|}{907.52} & \multicolumn{2}{|c|}{$1,816.31$} \\
\hline $\mathrm{CC}$ & \multicolumn{2}{|c|}{0.9993} & \multicolumn{2}{|c|}{0.9994} & \multicolumn{2}{|c|}{0.9995} \\
\hline
\end{tabular}

B

\begin{tabular}{|c|c|c|c|c|c|c|}
\hline \multirow[b]{2}{*}{ Linearity } & \multicolumn{2}{|c|}{ Imp-4 } & \multicolumn{2}{|c|}{ Imp-5 } & \multicolumn{2}{|c|}{ Opicapone } \\
\hline & Conc. $(\mu \mathrm{g} / \mathrm{ml})$ & Area & $\begin{array}{c}\text { Conc. }(\mu \mathrm{g} / \\
\mathrm{ml})\end{array}$ & Area & $\begin{array}{c}\text { Conc. }(\mu g / \\
\mathrm{ml})\end{array}$ & Area \\
\hline Linearity-1 & 0.50 & 28,795 & 0.50 & 55,162 & 5.00 & $2,244,697$ \\
\hline Linearity-2 & 1.25 & 67,534 & 1.25 & 149,494 & 12.50 & $5,971,815$ \\
\hline Linearity-3 & 2.50 & 138,619 & 2.50 & 308,936 & 25.00 & $9,850,960$ \\
\hline Linearity-4 & 3.75 & 207,290 & 3.75 & 441,678 & 37.50 & $14,621,611$ \\
\hline Linearity-5 & 5.00 & 274,361 & 5.00 & 577,344 & 50.00 & $19,194,238$ \\
\hline Linearity-6 & 6.25 & 340,591 & 6.25 & 716,875 & 62.50 & $24,559,172$ \\
\hline Linearity-7 & 7.50 & 404,295 & 7.50 & 860,248 & 75.00 & $28,679,705$ \\
\hline Slope & \multicolumn{2}{|c|}{$54,131.96$} & \multicolumn{2}{|c|}{$114,430.96$} & \multicolumn{2}{|c|}{$379,503.13$} \\
\hline Intercept & \multicolumn{2}{|c|}{$1,681.90$} & \multicolumn{2}{|c|}{$6,088.62$} & \multicolumn{2}{|c|}{$450,638.76$} \\
\hline $\mathrm{CC}$ & \multicolumn{2}{|c|}{0.9999} & \multicolumn{2}{|c|}{0.9996} & \multicolumn{2}{|c|}{0.9992} \\
\hline
\end{tabular}




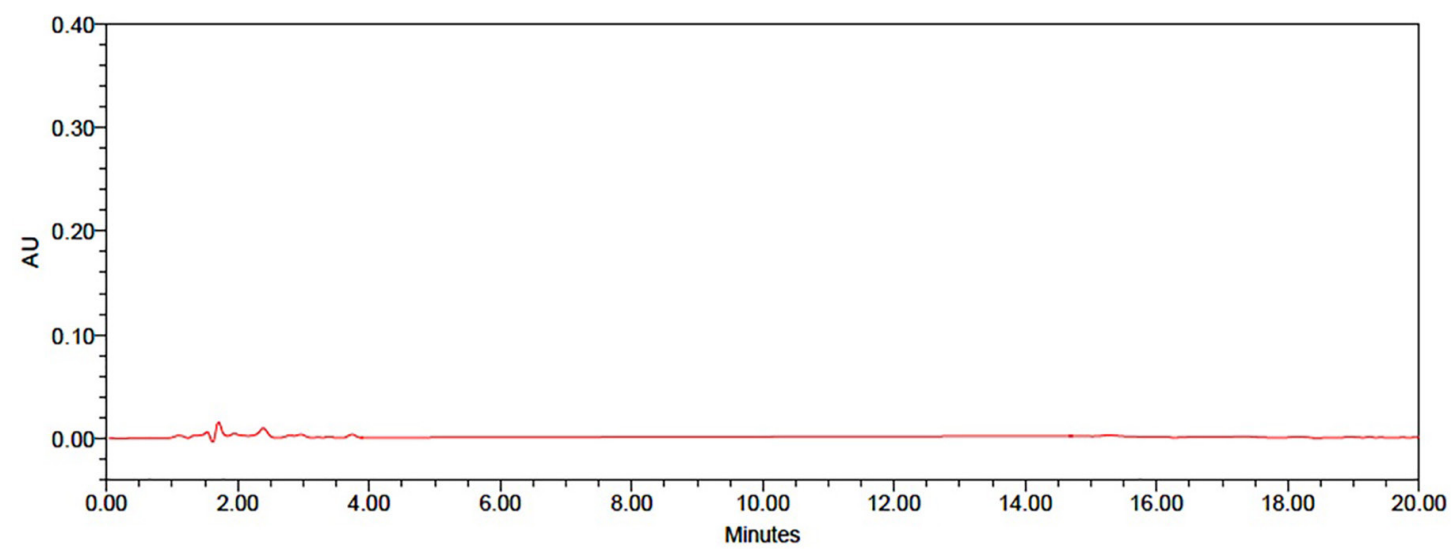

Figure 3. Chromatogramof blank.

its concentration. The calibration curve between $5-75 \mu \mathrm{g} / \mathrm{ml}$ of Opicapone and $0.5-7.5 \mu \mathrm{g} / \mathrm{ml}$ of each of imp-1, imp-2, imp-3, imp-4, and imp-5 revealed that the calibration curve was linear. The regression equations for calibration curve were $Y=379,503.15 x+450,638 .\left(R^{2}=0.9992\right)$ for Opicapone, $Y=50,691.95 x+2,263.91\left(R^{2}=0.9993\right)$ for imp-1, $Y=54,806.35 x+907.52\left(R^{2}=0.9994\right)$ for imp-2, $Y=23,404.21 x$ $+1,816.31\left(R^{2}=0.9995\right)$ for imp-3, and $Y=54,131.96 x+1,681.90$ $\left(R^{2}=0.9999\right)$ for imp-4, $Y=114,430.96 x+6,088.62\left(R^{2}=\right.$ 0.9996 ) for imp-5. Table 4 provide the results of linearity testing, and Figure 4 illustrates the calibration plots of Opicapone and its related substances.

\section{Accuracy}

The system's precision was gained by doing the recovery trials at three different points $(50 \%, 100 \%$, and

Table 5. Results of accuracy.

\begin{tabular}{ccc}
\hline S. no. & \% level & Opicapone \% recovery \\
\hline 1 & 50 & 99.5 \\
2 & 100 & 100.3 \\
3 & 150 & 99.9 \\
& Mean & 99.9 \\
& Std. dev. & 0.4 \\
\hline
\end{tabular}

Table 6. Intraday precision results of allantoin and permethrin.

\begin{tabular}{cccc}
\hline $\begin{array}{c}\text { Sample } \\
\text { no. }\end{array}$ & Spiked impurities & Total impurities & $\begin{array}{c}\text { \% Purity } \\
\text { (100-total } \\
\text { impurities) }\end{array}$ \\
\hline 1 & 4.32 & 0.41 & 99.59 \\
2 & 4.47 & 0.63 & 99.37 \\
3 & 4.28 & 0.57 & 99.43 \\
4 & 4.36 & 0.55 & 99.45 \\
5 & 4.44 & 0.37 & 99.63 \\
6 & 4.29 & 0.64 & 99.36 \\
Average & 4.36 & 0.53 & 99.47 \\
\% RSD & 1.82 & - & 0.11 \\
\hline
\end{tabular}

150\%). Active pharmaceutical ingredient (API) stock solutions with a 25, 50, and $75 \mu \mathrm{g} / \mathrm{ml}$ concentration of Opicapone were developed. To administer the test for each injection step, a different test solution was injected three times and was carried out according to the defined protocol. Both the recovery results and Relative Standard Deviation (RSD) values were $100 \%$ and under $\pm 2 \%$, respectively. The mean and standard deviation were found for the \% recovery. The results of accuracy studies are displayed in Table 5.

\section{Precision}

Measurements produced from several homogeneous mixture samplings can be highly precise, depending on the degree of precision of the analytical procedure. Six measurements of Opicapone and its related compounds were injected to calculate the precision of the medication delivery procedure. Method precision results were shown in Table 6 and sample chromatogram was shown in Figure 5.

\section{Intermediate precision}

The samples were evaluated by six different researchers, using different equipment, and were tested on days that varied. It is clear that the average percentage of RSD values is estimated based on the regional maximums. The findings are shown in Table 7.

Table 7. Inter-day precision results.

\begin{tabular}{cccc}
\hline $\begin{array}{c}\text { Sample } \\
\text { no. }\end{array}$ & Spiked impurities & Total impurities & $\begin{array}{c}\text { \% of related substances } \\
\text { (100-total } \\
\text { impurities) }\end{array}$ \\
\hline 1 & 4.23 & 0.32 & 99.68 \\
2 & 4.21 & 0.69 & 99.31 \\
3 & 4.29 & 0.66 & 99.34 \\
4 & 4.32 & 0.72 & 99.28 \\
5 & 4.15 & 0.41 & 99.59 \\
6 & 4.17 & 0.38 & 99.62 \\
Average & 4.23 & 0.53 & 99.47 \\
$\%$ RSD & 1.57 & - & 0.18 \\
\hline
\end{tabular}




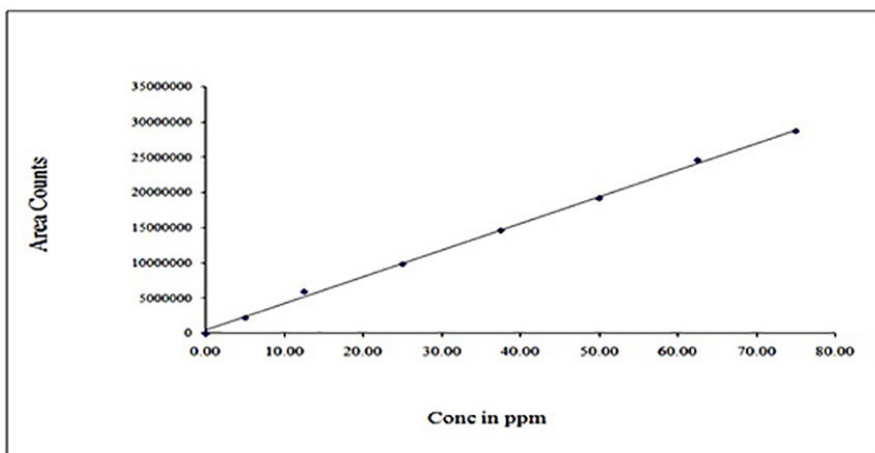

Opicapone

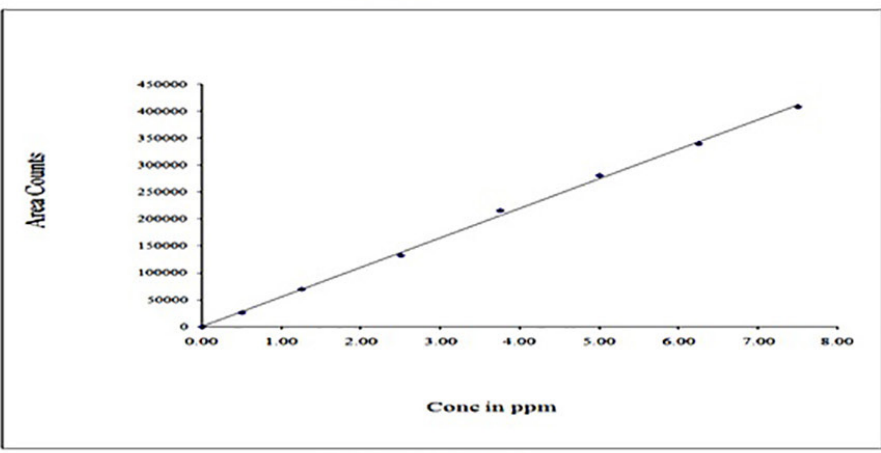

Opicapone Imp-2

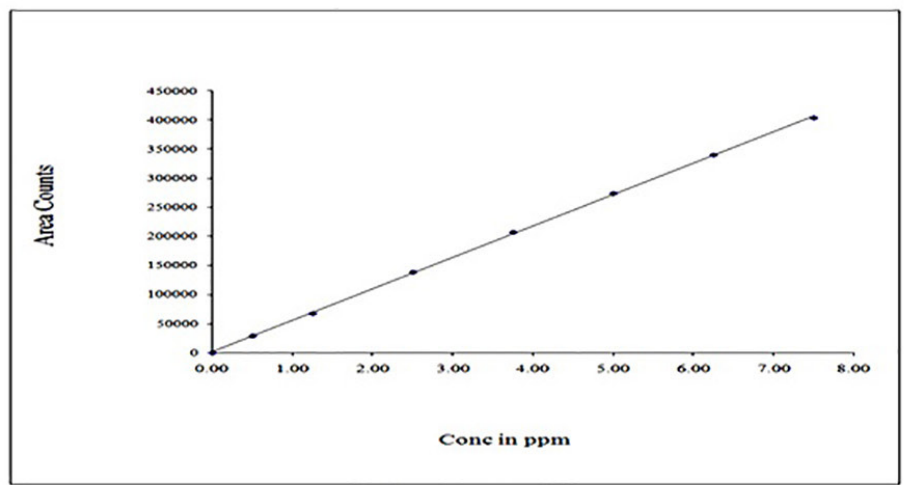

Opicapone Imp-4

Figure 4. Calibration plots of Opicapone and its impurities.

\section{LOD and LOQ}

The calibration curve technique was used to find LOD and LOQ independently. Using the RP-HPLC method devised

Table 8. Results of LOD and LOQ.

\begin{tabular}{ccccc}
\hline Name & LOD conc. $(\mu \mathrm{g} / \mathbf{m l})$ & $\mathbf{S} / \mathbf{N}$ & $\begin{array}{c}\text { LOQ conc. } \\
(\boldsymbol{\mu g} / \mathbf{m l})\end{array}$ & $\mathbf{S} / \mathbf{N}$ \\
\hline Opicapone & 0.063 & 7 & 0.21 & 38 \\
Imp-1 & 0.006 & 5 & 0.02 & 35 \\
Imp-2 & 0.006 & 5 & 0.02 & 35 \\
Imp-3 & 0.006 & 3 & 0.02 & 33 \\
Imp-4 & 0.006 & 4 & 0.02 & 34 \\
Imp-5 & 0.006 & 5 & 0.02 & 35 \\
\hline
\end{tabular}

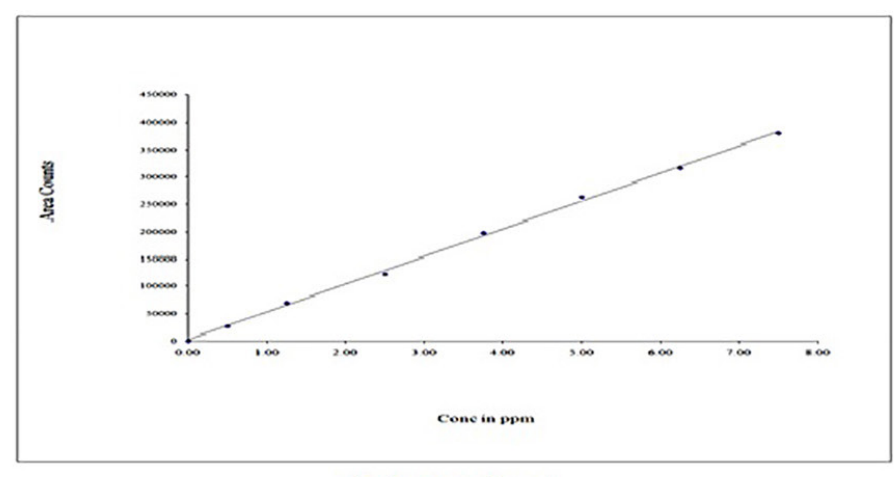

Opicapone Imp-1

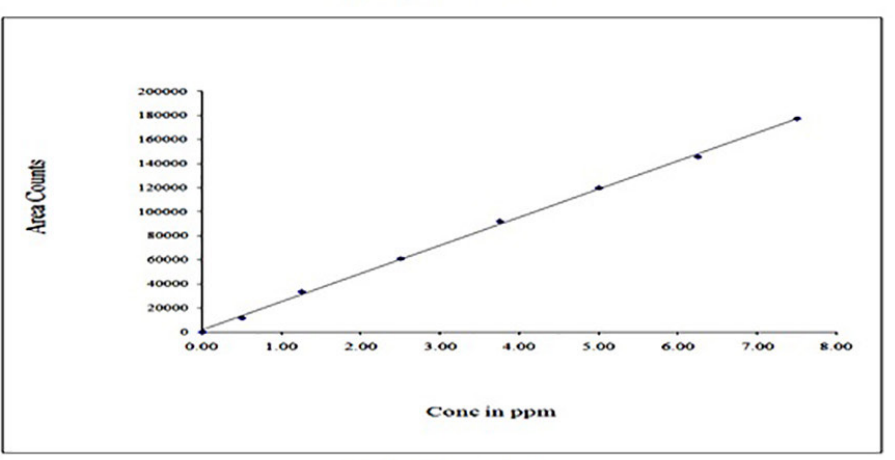

Opicapone Imp-3

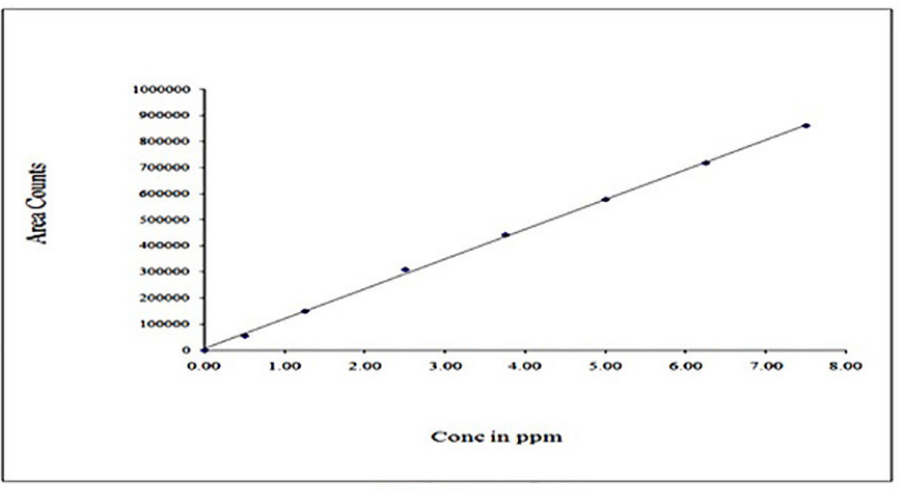

Opicapone Imp-5

for the chemical, the LOD and LOQ were evaluated by injecting a series of standard solution concentrations. The concentration levels of LOD and LOQ, as well as their respective Signal to noise ratio $(\mathrm{s} / \mathrm{n})$ values, were provided in Table 8.

\section{Robustness}

The experimental circumstances were varied to assess the robustness of variables that were modified on purpose, such as flow rate, mobile phase organic percentage, and more. As seen in Table 9, the Opicapone impurities as well as the material itself met the specifications for robustness.

\section{Stability}

At room temperature and $2^{\circ} \mathrm{C}-8^{\circ} \mathrm{C}$, normal solution can be stored for up to 24 hours. The solutions were then fed into the system and the \% variation was measured from the initial to 24 


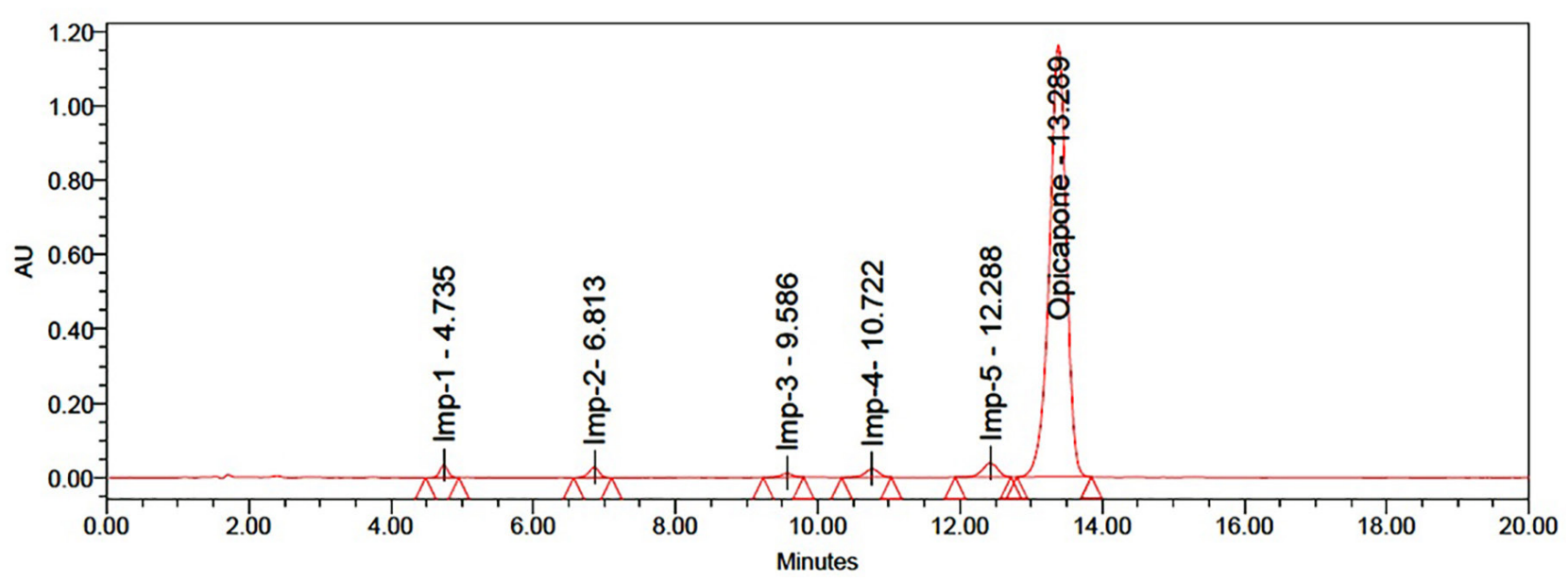

Figure 5. Chromatogram of sample.

hours. It was confirmed that no significant variation occurred, and that the solutions were stable for up to 24 hours. The assay's percentage did not reach $2 \%$. There is no impact on Opicapone and its byproducts regardless of storage circumstances. The results of the stability testing were shown in Table 10.

\section{Degradation studies}

To study the effects of partially degraded Opicapone, the chemical was exposed to a number of experimental situations. For research purposes, degradation trials were forced on material to prove that the technique was appropriate for being used in degraded goods. Another important aspect of the studies is information on the environment in which the medicine is unstable, therefore methods to reduce potential instabilities are also implemented during formulation. Degradation results were shown in Table 11.

Acid degradation. One millilitre of sample stock solution and $1 \mathrm{ml}$ of impurity stock solution were transferred to a 10 -ml volumetric flask, with $1 \mathrm{ml}$ of $1 \mathrm{~N} \mathrm{HCl}$ added and allowed to sit for 15 minutes. Make the diluent to the mark and add $1 \mathrm{ml}$ of 1

Table 9. Robustness results.

\begin{tabular}{cc}
\hline Parameter name & \% RSD \\
\cline { 2 - 2 } & Opicapone \\
\hline Flow rate $(0.8 \mathrm{ml} /$ minute $)$ & 0.78 \\
Flow rate $(1.2 \mathrm{ml} /$ minute $)$ & 0.43 \\
Org plus $(+10 \%)$ & 1.13 \\
Org minus $(-10 \%)$ & 0.86 \\
\hline
\end{tabular}

Table 10. Stability results of Opicapone.

\begin{tabular}{ccc}
\hline \multirow{2}{*}{ Stability } & \multicolumn{2}{c}{ Opicapone } \\
\cline { 2 - 3 } & \% purity & \% deviation \\
\hline Initial & 99.9 & 0.1 \\
6 hours & 99.5 & 0.5 \\
12 hours & 99.2 & 0.8 \\
18 hours & 98.5 & 1.5 \\
24 hours & 98.3 & 1.7 \\
\hline
\end{tabular}

$\mathrm{N} \mathrm{NaOH}$ after waiting 15 minutes. Use a syringe filter to filter the solution, then inject it into the HPLC system.

Alkali degradation. One millilitre of sample stock solution $1 \mathrm{ml}$ of impurity stock solution were transferred to a 10$\mathrm{ml}$ volumetric flask, with $1 \mathrm{ml}$ of $1 \mathrm{~N} \mathrm{NaOH}$ added and allowed to sit for 15 minutes. Make the diluent to the mark and add $1 \mathrm{ml}$ of $1 \mathrm{~N} \mathrm{HCl}$ after waiting 15 minutes. Use a syringe filter to filter the solution, then inject it into the HPLC system.

Peroxide degradation. Add $1 \mathrm{ml}$ of the impurity stock solution to a 10-ml volumetric flask and transfer $1 \mathrm{ml}$ of the sample stock solution to the same flask. Finally, add $1 \mathrm{ml}$ of $30 \%$ hydrogen peroxide solution to the volumetric flask and then dilute to the mark with a suitable solvent. Use a syringe filter to filter the solution, then inject it into the HPLC system.

Reduction degradation. To prepare a $10 \mathrm{ml}$ volumetric flask, move $1 \mathrm{ml}$ of sample stock solution and $1 \mathrm{ml}$ of impurity stock solution. Add $1 \mathrm{ml}$ of $30 \%$ sodium bi sulphate solution and top off with diluents. Use a syringe filter to filter the solution, then inject it into the HPLC system.

Thermal degradation. The sample solution was set in an oven at $105^{\circ} \mathrm{C}$ for 6 hours. The resultant solution was injected into HPLC system.

Hydrolysis degradation. To prepare a $10 \mathrm{ml}$ volumetric flask, move $1 \mathrm{ml}$ of sample stock solution and $1 \mathrm{ml}$ of impurity stock solution. Add $5 \mathrm{ml}$ of HPLC water and top off with diluents. Use a syringe filter to filter the solution, then inject it into the HPLC system.

Table 11. Forced degradation results.

\begin{tabular}{cc}
\hline Degradation condition & Opicapone \\
\cline { 2 - 2 } & Percent of degradation \\
\hline Acid deg & 13.2 \\
Alkali deg & 12.4 \\
Peroxide deg & 15.2 \\
Reduction deg & 11.3 \\
Thermal deg & 0.4 \\
Hydrolysis deg & 0.5 \\
\hline
\end{tabular}




\section{CONCLUSION}

A developed method gives very good results in 20 minutes, has high efficiency, and complies with the System suitability tests (SST) modifications of United States Pharmacopeia (USP) for Opicapone and its related impurities. The present work demonstrates the efficacy of the Agilent Eclipse C18 column, which provides better resolution, lower plate count, and lower tailing in elution of analytes. In contrast, because of their low tolerance to extractables, $\mathrm{C} 18$ columns can achieve high specificity in a shorter time when studying Opicapone per ICH Q3A (R2) guidelines. The proposed method for the simultaneous determination and quantification of Opicapone and its impurities was found to be simple, precise, accurate, linear, robust, and fast. The accuracy of the sample recovery agreed with the labelling claims, leading to the assumption of no interference during the estimation. By using AGREE metrics tool (0.78), we concluded that the method is green and used for impuirites detection.

\section{ACKNOWLEDGEMENT}

The authors are thankful to D. Ramchandran for giving his valuable guidance and suggestions and also Shree Icon Pharmaceutical Laboratories for providing laboratory facilities to finish this research work.

\section{AUTHOR CONTRIBUTIONS}

All authors made substantial contributions to conception and design, acquisition of data, or analysis and interpretation of data; took part in drafting the article or revising it critically for important intellectual content; agreed to submit to the current journal; gave final approval of the version to be published; and agree to be accountable for all aspects of the work. All the authors are eligible to be an author as per the international committee of medical journal editors (ICMJE) requirements/guidelines.

\section{FUNDING}

There is no funding to report.

\section{CONFLICTS OF INTEREST}

The authors report no financial or any other conflicts of interest in this work.

\section{ETHICAL APPROVALS}

This study does not involve experiments on animals or human subjects.

\section{PUBLISHER'S NOTE}

This journal remains neutral with regard to jurisdictional claims in published institutional affiliation.

\section{REFERENCES}

Ananth J, Parameswaran S, Gunatilake S, Burgoyne K, Sidhom T. . J Clin Psychiatry, 2004; 65(4):464-70.

Barranco Quintana JL, Allam MF, Del Castillo AS, Navajas RF. Parkinson's disease and tea: a quantitative review. J Am Coll Nutr, 2009; 28(1):1-6.

Bharucha AE. Constipation. Best Pract Res Clin Gastroenterol, 2007; 21(4):709-31.

Bonifácio MJ, Palma PN, Almeida L, Soares-da-Silva P. . CNS Drug Rev, 2007; 13(3):352-79.
Brewster LM. . Purinergic Signal, 2020; 16(3):305-12.

Chisholm P, Anpalahan M. Orthostatic hypotension: pathophysiology, assessment, treatment and the paradox of supine hypertension. Intern Med J, 2017; 47(4):370-9.

Daniela Gonçalves, Gilberto Alves, Ana Fortuna et al. An HPLC-DAD method for the simultaneous quantification of opicapone (BIA 9-1067) and its active metabolite in human plasma. The Royal society of Chemistry, 2013; 138(8):2463-9.

Daniela Goncalves, Gilberto Alves, Patrício Soares-da-Silva et al. Bioanalytical chromatographic methods for the determination of catechol-O-methyltransferase inhibitors in rodents and human samples: A review. Analytica Chimica Acta, 2012; 710:17-32.

Eisenhofer G, Kopin IJ, Goldstein DS. Catecholamine metabolism: a contemporary view with implications for physiology and medicine. Pharmacol Rev, 2004; 3(56):331-49.

Fabbrini G, Brotchie JM, Grandas F, Nomoto M, Goetz CG. Levodopa-induced dyskinesias. Mov Disord, 2007; 22(10):1379-89.

Gillman PK. A reassessment of the safety profile of monoamine oxidase inhibitors: elucidating tired old tyramine myths. J Neural Transm, 2018; 125(11):1707-17.

Glatt SJ, Faraone SV, Tsuang MT. Association between a functional catechol O-methyltransferase gene polymorphism and schizophrenia: meta-analysis of case-control and family-based studies. Am J Psychiatry, 2003; 160(3):469-76.

Hamidi O, Young WF, Gruber L Smestad J, Yan Q, Ponce OJ, Prokop L, Murad MH, Bancos I. . Clin Endocrinol, 2017; 87(5):440-50.

Hussain T, Lokhandwala MF. Renal dopamine receptors and hypertension. Exp Biol Med, 2003; 228(2):134-42.

Lopez VM, Decatur CL, Stamer WD, Lynch RM, McKay BS. PLOS Biol, 2008; 6(9):e236.

Low PA. Neurogenic orthostatic hypotension: pathophysiology and diagnosis. Am J Manag Care, 2015; 21(13 Suppl):s248-57.

Macleod AD, Taylor KS, Counsell CE. . Mov Disord, 2014; 29(13):1615-22.

Moghadam-Kia S, Oddis CV, Aggarwal R. . Cleve Clin J Med, 2016; 83(1):37-42

Scholz H, Trenkwalder C, Kohnen R, Kriston L, Riemann D, Hornyak M. Levodopa for restless legs syndrome. Cochrane Database Syst Rev, 2011; (2):CD005504.

Stahl SM, Felker A. Monoamine oxidase inhibitors: a modern guide to an unrequited class of antidepressants. CNS Spectr, 2014; 13(10):855-71.

Strawn JR, Keck PE, Caroff SN. Neuroleptic malignant syndrome. Am J Psychiatry, 2007; 164(6):870-6.

Tevosian SG, Ghayee HK. Pheochromocytomas and paragangliomas. Endocrinol Metab Clin North Am, 2019; 48(4):727-50.

Thanvi B, Lo N, Robinson T. . Postgrad Med J, 2007; 83(980):384-88

Warren JD, Blumbergs PC, Thompson PD. Rhabdomyolysis: a review. Muscle Nerve, 2002; 25(3):332-47.

How to cite this artilcle:

Dittakavi R, Tirumalasetty N. Development and validation of a stability indicating related substances of Opicapone by reverse phase high performance liquid chromatography and its degradation. J Appl Pharm Sci, 2022; 12(02):179-186. 